\title{
The role of benzoate secreted by Desulfotomaculum acetoxidans DSM 771 in sulfate uptake
}

\author{
Lucyna Pawłowska-Ćwięk ${ }^{\bowtie}$ and Ryszard Pado

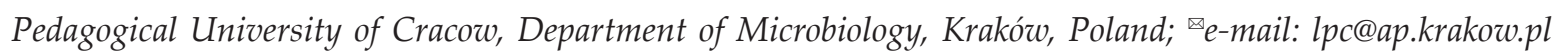

Received: 30 January, 2004; revised: 24 March, 2005; accepted: 13 October, 2005

available on-line: 25 October, 2005

\begin{abstract}
This work was designed to find the cause of the delay in hydrogen sulfide dissimilation in Desulfotomaculum acetoxidans DSM 771, which is dependent on the sulfate uptake. This bacterium grown without addition of any aromatic compound was shown by spectrum analysis with the methylene method to contain hydroxy-benzoate derivatives. The presence of these compounds was confirmed by HPLC in fractions obtained from cell walls after 15 days of culture. The test with 2,2'-azino-bis(3-ethylbenzothiazoline-6-sulfonic acid) diammonium salt seemed to indicate the presence of peroxidase, which probably oxidized benzoate to its hydroxy derivatives. The test with 5-sulfo-salicylic acid proved the ability of the investigated strain to utilize arylsulfates and to reduce sulfate group to hydrogen sulfide. On the basis of the above data, we propose the following sequence of reactions: 1 , benzoate secretion; 2, benzoate hydroxylation; 3 , sulfonation of hydroxy-benzoate derivatives.
\end{abstract}

Keywords: benzoate secretion, oxidation, sulfonation

The sulfate-reducing bacteria (SRB - group 7) (Widdel \& Pfennig, 1984) are capable not only of sulfur assimilation but also of dissimilative reduction of sulfate or sulfur. This specific pathway is coupled with utilization of hydrocarbon derivatives (e.g. lactate):

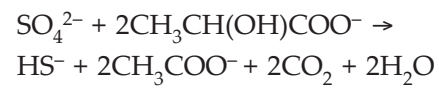

However, the species Desulfotomaculum acetoxidans is also capable of complete oxidation of acetate, which can contribute to survival of these bacteria.

Sulfate transport has been the most comprehensively investigated in Gram-negative bacteria (e.g., Escherichia coli and Salmonella sp.) (Silver \& Walderhaung, 1992). In these bacteria, sulfate transport into the cell is catalyzed either by ATP-binding cassette (ABC)-type transporters (SulT family) or by major facilitator superfamily-type transporters (SulP family) (Kertesz, 2001). Unfortunately, sulfate uptake processes in SRB are still very poorly understood although these bacteria obtain energy also from the anaerobic respiratory chain of sulfate metabolism. On the basis of the increase in hydrogen ion concentration accompanied by a simultane- ous decrease only in sulfate level, Cypionka (1987) concluded that sulfate uptake by the sulfate-reducing bacteria took place by a symport with hydrogen protons. Several researchers confirmed the lowering of the media $\mathrm{pH}$ during the first days (1-3) of culture in the lag phase (Cypionka, 1989; Pado et al., 1994). However, Raskin et al. (1996) investigating co-cultures of sulfate-reducing and methanogenic bacteria found that such microorganisms could survive in culture for over two years. Interestingly, the addition of sulfate after such a long period did not cause immediate production of $\mathrm{H}_{2} \mathrm{~S}$. An increased $\mathrm{H}_{2} \mathrm{~S}$ level was only found in $\log$ and stationary phases (not earlier than after 3-4 days of culture), most probably as a product of a dissimilatory pathway (Pado \& Pawłowska-Ćwięk, 2004). The question arose of what caused the delay in $\mathrm{H}_{2} \mathrm{~S}$ production when the sulfate reduction process (especially at the bisulfite step) proceeded at a high rate (Postgate, 1984; LeGall \& Fauque, 1988; Moura et al., 1988).

On the other hand, it has been known for years that the sulfate-reducing bacteria are capable of biodegradation and catabolic utilization of different monoaryl derivatives, especially benzoate and 4-hydroxy-benzoate (Kuever et al., 1993), under anaerobic conditions (Schnell et al., 1989; Schink et

Abbreviations: ABTS, 2,2'-azino-bis(3-ethylbenzothiazoline-6-sulfonic acid) diammonium salt; SRB, sulfate-reducing bacteria. 
al., 1992; Gorny \& Schink, 1994; Rabus \& Widdel, 1995; Fuseler et al., 1996). However, it is still not clear in what way those obligatory anaerobes can oxidize benzoate, which is required for such biodegradation (Schink et al., 1992) (Fig. 1).

The above findings prompted us to make an attempt to explain the reasons of the delay of $\mathrm{H}_{2} \mathrm{~S}$ dissimilation. Desulfotomaculum acetoxidans (subgroup 1) was selected for the tests, because it is a Gram-positive bacterium and thus is a more convenient object of laboratory studies than Gram-negative SRB (e.g., Desulfovibrio sp.), which require of additional purification procedures.

\section{MATERIALS AND METHODS}

Growth of organisms. Cultures of Desulfotomaculum acetoxidans DSM 771 were maintained on a medium containing (per $1 \mathrm{dm}^{3}$ ): $1.15 \mathrm{mM} \mathrm{KH} \mathrm{KO}_{4^{\prime}}$ $4.02 \mathrm{mM} \mathrm{KCl}, 5.61 \mathrm{mM} \mathrm{NH} \mathrm{Cl}_{4}, 1.13 \mathrm{mM} \mathrm{CaCl}_{2}$, $1.97 \mathrm{mM} \mathrm{MgCl}_{2}, 85.55 \mathrm{mM} \mathrm{NaCl}$, trace elements (according to DSM-bank prescription) and additionally $21.12 \mathrm{mM}$ sodium sulfate and $42.24 \mathrm{mM}$ sodium lactate as substrates; without any addition of aromatic compounds; $\mathrm{pH}$ of the media were adjusted to 7.0 \pm 0.2 . The autoclaved and inoculated media were immediately covered with a liquid paraffin layer 3-5 mm thick. Some cultures were grown with the addition of $21.12 \mathrm{mM}$ 5-sulfo-salicylate without lactate and sulfate. All cultures were grown at room temperature $\left(19-24^{\circ} \mathrm{C}\right)$.

Turbidity of cultures was measured at $436 \mathrm{~nm}$ (Cypionka, 1987) and the growth rate was estimated from turbidity measured on consecutive days of culture $\left(\tau_{t_{n}}\right)$ relative to the initial turbidity of that culture $\left(\tau_{t_{0}}\right)$.

Cell wall preparation procedure. On the 1st and 15th culture day, $1 \mathrm{dm}^{3}$ aliquots were withdrawn and centrifuged at $2500 \times g$ for $25 \mathrm{~min}$. Cell biomass pallets were thrown away, while the supernatants were evaporated with several crystals of sodium dithionite $\left(\mathrm{Na}_{2} \mathrm{~S}_{2} \mathrm{O}_{4}\right)$ to about $50 \mathrm{ml}$ at $8^{\circ} \mathrm{C}$. The separated cell wall pellets were centrifuged at 10000 $\times g$ for $15 \mathrm{~min}$ and lysozyme solution $\left(10^{5} \mathrm{U} / 1 \mathrm{~cm}^{3}\right.$ $10 \mathrm{mM}$ Tris buffer, $\mathrm{pH}$ 6.9) was added to the pellet to degrade peptidoglycan. The suspension was shaken and incubated for $48 \mathrm{~h}$ and recentrifuged. Then the pellets were extracted with $2 \mathrm{mM}$ piperazine- $N, N^{\prime}$-bis(2-ethane-sulfonic acid) (Pipes) buffer

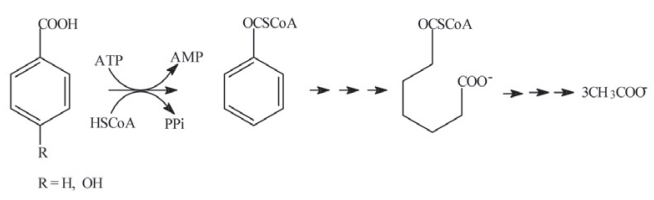

Figure 1. Simplified scheme of the probable path of monoaryls biodegradation by sulfate-reducing bacteria.
( $\mathrm{pH}$ 5.5) for $24 \mathrm{~h}$. This operation was repeated three times and the extracts were pooled.

The supernatants following the $\mathrm{Na}_{2} \mathrm{~S}_{2} \mathrm{O}_{4}$ treatment were evaporated to form crystals and were treated with $100 \mathrm{~cm}^{3}$ of methanol for $8 \mathrm{~h}$ and centrifuged as previously.

Chemical determinations. Hydrogen sulfide level during incubation was estimated by the methylene blue method with reagent A (1 g of $N, N-$ dimethyl-p-phenylenediamine/100 $\mathrm{cm}^{3}$ of $6 \mathrm{M} \mathrm{HCl}$ ) and reagent $\mathrm{B}\left(10 \mathrm{~g}\right.$ of $\mathrm{FeNH}_{4}\left(\mathrm{SO}_{4}\right)_{2} / 100 \mathrm{~cm}^{3}$ of $2 \mathrm{M}$ $\mathrm{HCl}$ ) (Fago \& Popowsky, 1949). In order to verify the presence of peroxidase, the modified method of Szutowicz et al. (1984) was used. Briefly, to $1 \mathrm{~cm}^{3}$ of Pipes extract (treated with lysozyme as above), 5 mM 2,2'-azino-bis(3-ethylbenzothiazoline-6-sulfonic acid) (ABTS) in $20 \mathrm{mM}$ phosphate-citrate buffer (pH 5.0) and $5 \mathrm{mM} \mathrm{H}_{2} \mathrm{O}_{2}$ were added (1:1:1, by vol.). After $1 \mathrm{~h}$ spectral analysis was performed using $5 \mathrm{U}$ of a peroxidase standard as a control. Moreover, chemical tests with chromic acid $(5 \mathrm{~g})$ in $100 \mathrm{~cm}^{3}$ of $1 \mathrm{M}$ sulfuric acid were carried out for preliminary identification of phenolic compounds.

Spectrophotometric analysis. The colorimetric and spectral analyses were performed using a CECIL 8020 spectrophotometer (bandwidth $2 \mathrm{~nm}$ and path length $10 \mathrm{~mm}$ ), and data were processed with the computer program DataStream-Plus (both Cecil Instruments Ltd).

High-pressure liquid chromatography (HPLC). The methanol extract (from crystals) from the 15-day culture was separated by HPLC (ISCO Company) on a DAVISIL SI $10 \mathrm{U}$ preparative $(250 \times$ $22 \mathrm{~mm}$ ) column at a flow rate of $12 \mathrm{~cm}^{3} / \mathrm{min}$ in a linear $\mathrm{pH}$ range 9.0 (base water) - 3.5 (acidic methanol). Fractions were detected at $255 \mathrm{~nm}$ using a UV/ VIS detector and collected using a Foxy 200 fraction collector. We determined the elution times of acidic aryl standards and compared them with the obtained test fractions: 4-hydroxy-3-sulfo-benzoic acid 3.25-3.75 $\mathrm{min}$ (fraction 10: 3.5-3.75 $\mathrm{min}$ ), 4-hydroxybenzoic acid 3.75-4.25 min (fraction 11: 3.75-4.00), benzoic acid 4.25-4.75 $\mathrm{min}$ (fraction 14: 4.5-4.75 min). 4-Hydroxy-3-sulfo-benzoic acid was obtained according to Barth (1871) and purified by HPLC.

The chemicals and reagents (except for 4-hydroxy-3-sulfo-benzoate) were obtained from Merck, Fluka or Sigma Chemical Companies.

\section{RESULTS AND DISCUSSION}

Growth rate and $\mathrm{H}_{2} \mathrm{~S}$ (and/or sulfide) level during incubation of Desulfotomaculum acetoxidans are presented in Fig. 2.

Several researchers have proven that some species of sulfate-reducing bacteria are able to degrade derivatives of amine-, methyl-, and hydroxy- 


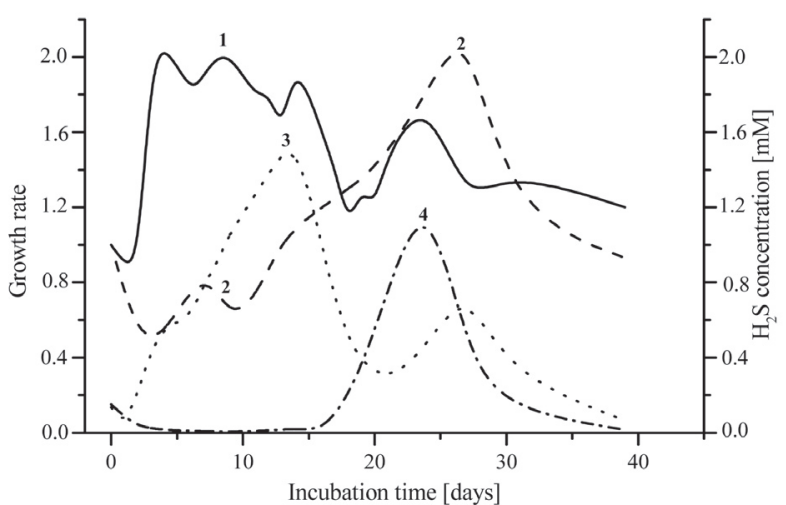

Figure 2. Growh rate and $\mathrm{H}_{2} \mathrm{~S}$ level during cultivation of Desulfotomaculum acetoxidans.

1, Growth rate in medium with sulfate and lactate; 2 growth rate with 5-sulfo-salicylate; $3, \mathrm{H}_{2} \mathrm{~S}$ level in medium with sulfate and lactate; $4, \mathrm{H}_{2} \mathrm{~S}$ level in medium with 5-sulfo-salicylate.

benzene (Schnel et al., 1989; Schink et al., 1992; Gorny \& Schink, 1994; Rabus \& Widdel, 1995). Kuever et al. (1993) claimed that a strain called Groll (a new species of the genus Desulfotomaculum) utilized benzoate and 4-hydroxy-benzoate so fast that the lag growth phase was not observed at all, whereas the degradation of 3-hydroxy-benzoate and 3,4-dihydroxy-benzoate needed more than $60 \mathrm{~h}$. Utilization of other aryls, among them phenol, $o$-dihydroxy-benzene, $m$ and $p$-cresol and hydroxy-benzylalcohols required even up to 8 days. Since benzoate and 4-hydroxybenzoate are utilized with similar easiness and velocity, two basic questions need to be answered: which enzyme catalyzes the hydroxylation of benzoate and whether this reaction proceeds inside or outside the cytosol.

Samples from the first days of incubation (lag phase) temporarily turned pink (salmon) when reagents $A$ and $B$, used for the determination of $\mathrm{H}_{2} \mathrm{~S}$, were added (see chemical tests). This prompted us

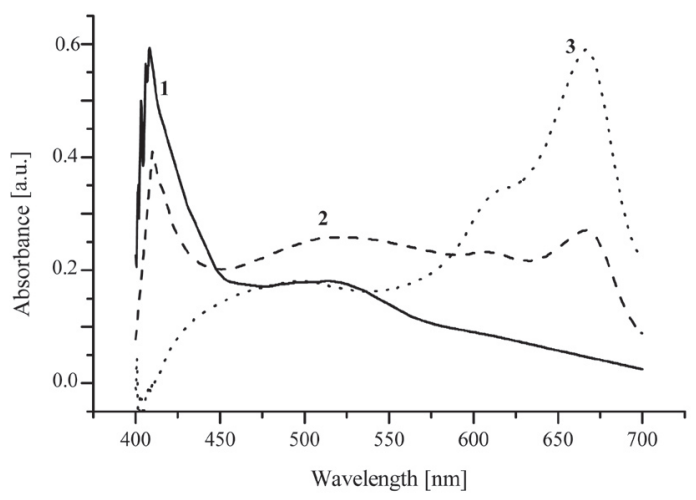

Figure 3. Absorption spectra of culture samples.

1 (1, with maxima at: 407.2, 410.9 and $512.0 \mathrm{~nm}), 2$ (2, 411.2; 520.1 and $667.0 \mathrm{~nm}$ ), and 3 (3, 503.2 and 666.7 $\mathrm{nm}$ ) days samples with methylene blue method's reagents $N, N$-dimethyl-p-phenylenediamine (reagent A) and $\mathrm{Fe}\left(\mathrm{NH}_{4}\right)\left(\mathrm{SO}_{4}\right)_{2}$ (reagent $\mathrm{B}$ ). to perform a spectral analysis. Spectra were obtained in the range 400-700 $\mathrm{nm}$ for samples collected after 24, 48 and $72 \mathrm{~h}$ of culture and treated with reagents $\mathrm{A}$ and $\mathrm{B}$. They revealed two clear maxima at about $410 \mathrm{~nm}$ and about $665 \mathrm{~nm}$ and a much less pronounced one at about $505 \mathrm{~nm}$ (Fig. 3). It was very interesting that during the study period the peak at about $410 \mathrm{~nm}$ decreased whereas the peak at about $665 \mathrm{~nm}$ increased. The maximum at about $665 \mathrm{~nm}$ is characteristic of methylene blue, which is a product of the reaction of hydrogen sulfide with the reagents used in the method. Obviously, during the consecutive days of incubation the absorbance at $665 \mathrm{~nm}$ was permanently increasing, which proved an increased level of $\mathrm{H}_{2} \mathrm{~S}$. These results correspond well with our earlier research concerning the beginning of the dissimilatory pathway (Pado \& PawłowskaĆwięk, 2004). The delay of $\mathrm{H}_{2} \mathrm{~S}$ dissimilation can be a result of the metabolic priority of an assimilation pathway of sulfate reduction, however, other causes should not be disregarded.

Most of the standards (4-hydroxy-benzoate, 5sulfo-salicylate and 4-hydroxy-3-sulfobenzoate - see Materials and Methods), but not benzoate, formed complexes with $\mathrm{Fe}^{3+}$ present in reagent $\mathrm{B}$ with the maxima in their absorption spectra at $411.7 \mathrm{~nm}$, 503.5 and $501.2 \mathrm{~nm}$, respectively (Fig. 4). Based on these data, the results of bacterial cell wall analysis most likely suggest the presence of 4-hydroxy-benzoate whose amount seems to decrease progressively after $24 \mathrm{~h}$ of incubation (Fig. 3). The small peak at about $505 \mathrm{~nm}$ can indicate the presence of a sulfate derivative of 4-hydroxy-benzoate rather than salicylate (compare Figs. 3 and 4).

The methanol extract from crystals obtained from the 15-day culture was fractionated by HPLC. The obtained fractions were subjected to spectral analysis and chemical tests. Peaks of initial fractions (9-16) had absorbance maxima in the range 253-262

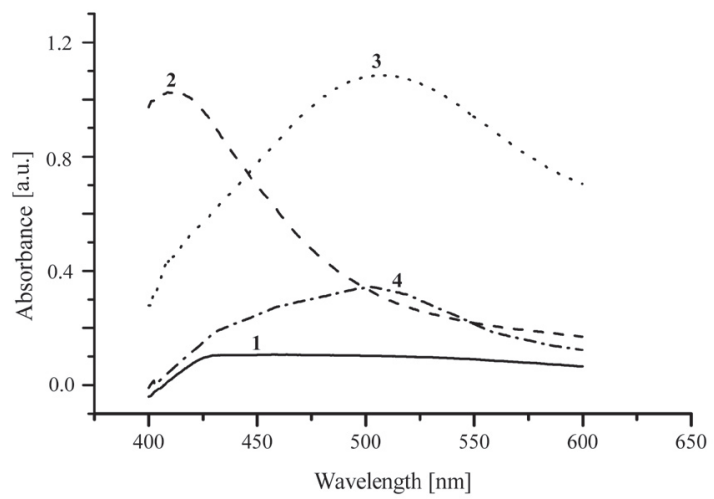

Figure 4. Absorption spectra of aromatic compound standards.

Benzoate (1), 4-hydroxy-benzoate (2, maximum at 411.4 $\mathrm{nm})$, 5-sulfo-salicylate $(3,503.5 \mathrm{~nm})$ and 4-hydroxy-3-sulfobenzoate $(4,501.2 \mathrm{~nm})$ using the methylene blue reagent B. 


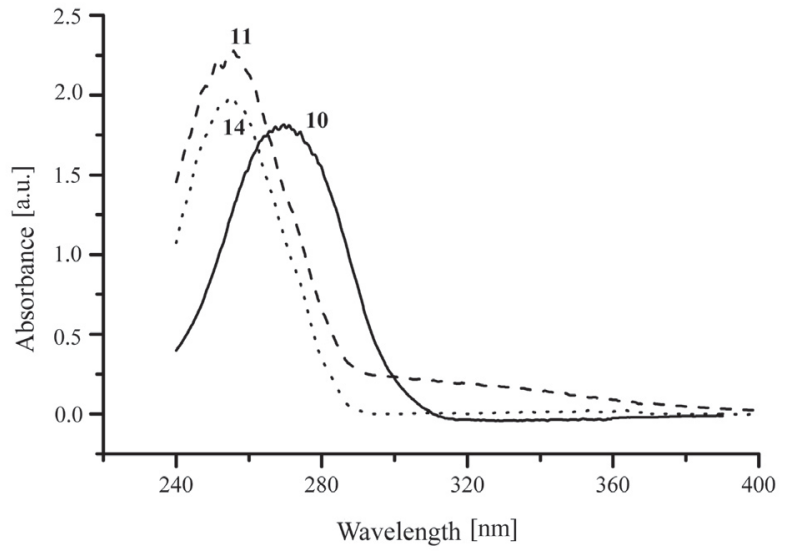

Figure 5. Absorption spectra of cell wall fractions. $10(262.1 \mathrm{~nm}), 11(255.3$ and $258.0 \mathrm{~nm})$ and $14(255.6 \mathrm{~nm})$ obtained by HPLC.

$\mathrm{nm}$, which is characteristic of benzoate derivatives. The obtained results indicate the presence of at least two compounds of that type (Fig. 5). The phenolic character of those compounds was confirmed by preliminary identification with chromic acid. Fractions obtained by repeated HPLC were treated with reagent $\mathrm{B}$. The absorption spectra showed the presence of ferrous complexes with 4-hydroxy-3-sulfobenzoate (fraction 10) and 4-hydroxy-benzoate (fraction 11) (Fig. 6). The poorly distinguished peak at $502 \mathrm{~nm}$ (fraction 10) may suggest fast transport of 4-hydroxy-3-sulfo-benzoate into the cytosol.

The UV/VIS spectrum of the Pipes buffer extract from the cell wall precipitate from the 1-day culture was characterized by maxima at 417,525 and $551 \mathrm{~nm}$ (Fig. 7). The test with the use of ABTS and $\mathrm{H}_{2} \mathrm{O}_{2}$, which are specific reagents for peroxidase, was performed (Fig. 8). The obtained results seem to indicate that the protein exhibiting peroxidase activity which appeared in the investigated bacteria is similar to horseradish peroxidase. This cell wall protein, and particularly its catalytic specificity, requires further research. The hydroxyl group position seems to be important since 4-hydroxy-benzoate

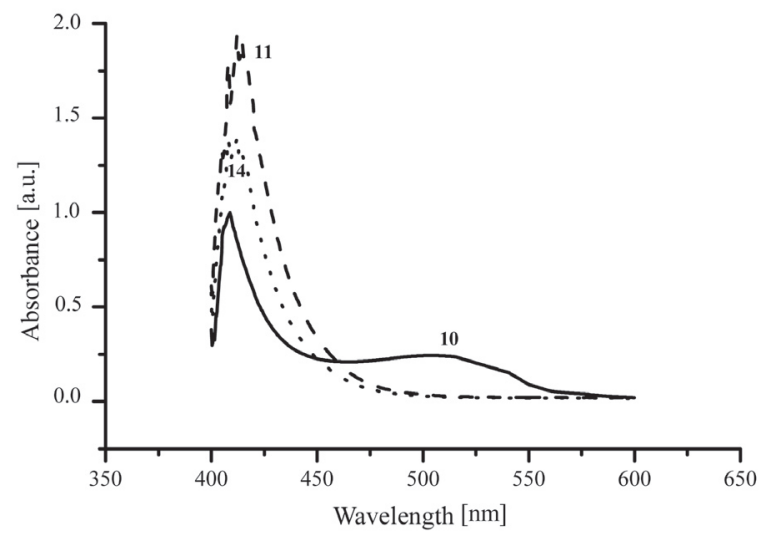

Figure 6. Absorption spectra of cell wall fractions. 10 (408.7 and $502.0 \mathrm{~nm}), 11$ (407.5 and $412.0 \mathrm{~nm})$ and 14 (408.4 and $412.0 \mathrm{~nm}$ ) with reagent B.

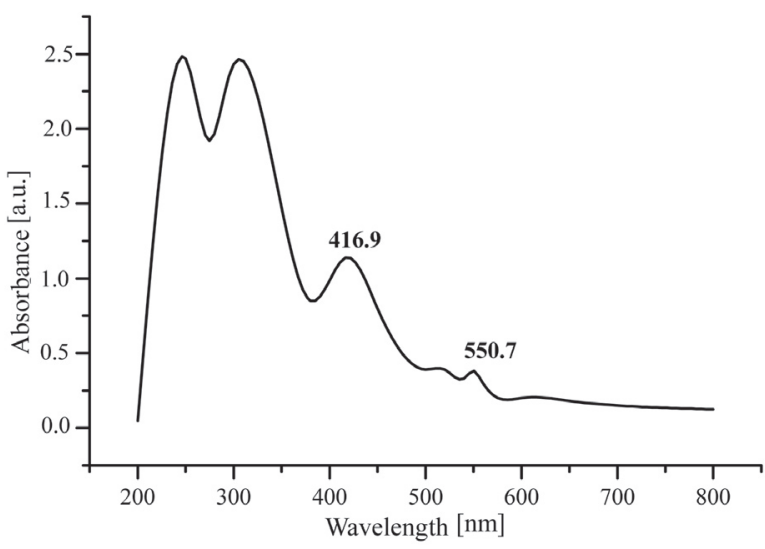

Figure 7. Absorption spectrum of Pipes buffer extract of 1-day culture treated with $10^{5} \mathrm{U}$ lysozyme.

was utilized faster than 3-hydroxy-benzoate (Kuever et al., 1993). One should remember that 4-hydroxybenzoate is a product of an enzymatic reaction, while 3-hydroxy-benzoate may be produced in other ways as well. Probably the presence of a carboxylic group is also very important, because the growth of this bacterium on media with an aryl compound but without a $-\mathrm{COOH}$ group (e.g., phenol) is poor (Kuever et al., 1993). The carboxylic group binding to transport proteins could make transport processes into the cytosol easier and faster.

However, regardless of the aryl substituent groups, a dual function can be ascribed to this bacterial peroxidase. Firstly, it can be one of antioxidizing enzymes (existing outside the cytosol), which is essential for these obligatory anaerobes (Postgate, 1984; Widdel \& Pfennig, 1984; LeGall \& Fauque, 1988). Secondly, it can be responsible for catalyzing the oxidation of aromatic monomers, which can then be decomposed and utilized in different metabolic processes (Schnel et al., 1989; Schink et al., 1992; Gorny \& Schink, 1994; Rabus \& Widdel, 1995; Van Ommen Kloeke et al., 1995).

There must be a reason for the secretion of a high-energy metabolite, such as benzoate, into the

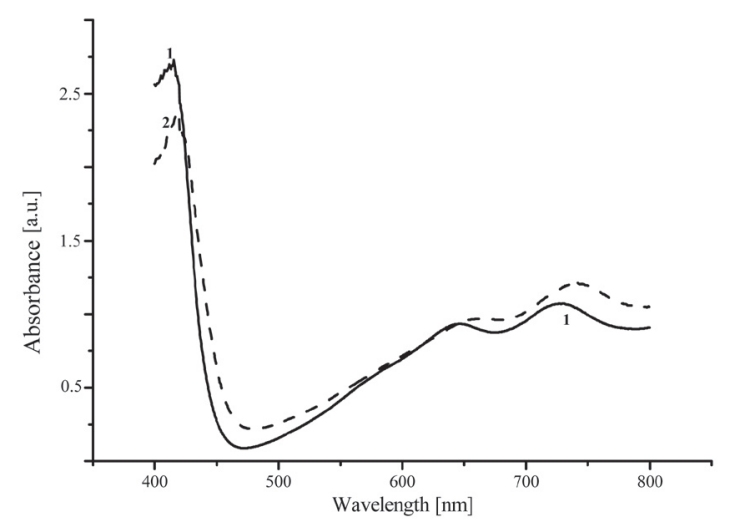

Figure 8. Absorption spectra of peroxidase samples. 1, $5 \mathrm{U}$ peroxidase standard; 2, Pipes extract of 1-day culture with $1.6 \mathrm{mM}$ ABTS and $1.6 \mathrm{mM} \mathrm{H}_{2} \mathrm{O}_{2}$. 


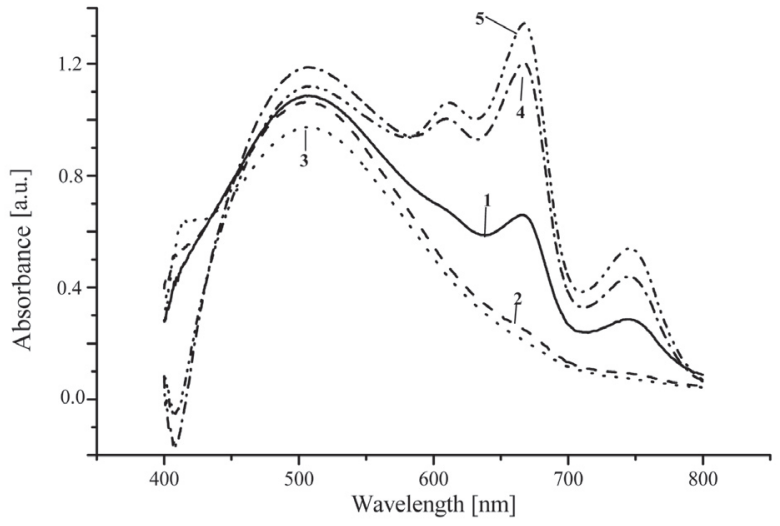

Figure 9. Absorption spectra of samples from culture cultivated with 5 -sulfo salicylate.

1 , inoculation day; 2, after 7 days; 3, after 11; 4, after 20 days; 5, after 23 days (2-fold dilution).

cell wall by the investigated strain. The possibility of sulfonation of hydroxyaryls is supported by the following facts: 1. Sulfonation of hydroxy-benzoates runs easily in the laboratory; 2 . Lowering of $\mathrm{pH}$ facilitates sulfonation and such lowering is characteristic of the lag phase; 3 . The peak appearing at ๑505 $\mathrm{nm}$ proves the presence of a 4-hydroxy-3-sulfo-benzoate complex with iron (compare Figs. 3 and 4).

Considering the above observations, 2-hydroxy-5-sulfo-benzoate (5-sulfo-salicylate) was used as the only source of sulfates and carbon in the growth medium. However, the growth rate and $\mathrm{H}_{2} \mathrm{~S}$ level increased earlier and quicker in a culture with lactate plus sulfate than in one with 5-sulfo-salicylate (Fig. 2). These results indicate that uptake (and maybe assimilation too) of 5-sulfosalicylate requires the longest time. The $\mathrm{H}_{2} \mathrm{~S}$ level (Fig. 2) and absorption spectra (Fig. 9) showed a steady increase starting from the 13th day of incubation. This leads us to believe that the investigated species has the ability of utilizing the sulfate group as a substrate for the sulfate reduction pathway. This supports the possibility of sulfonation reaction of hydroxy-benzoates. A significant prolongation of the delay of $\mathrm{H}_{2} \mathrm{~S}$ dissimilation when the culture was carried out with 5-sulfo-salicylate, in comparison with any monoaryl derivative, might indicate the necessity of shifting of the hydroxyl group from position 2 to position 4 in the ring.

The obtained data suggest the following sequence of processes occurring in cell walls during the lag phase of growth:

1. Secretion of benzoic acid or its derivatives (this step is not needed if those compounds are directly added to the medium);

2. Oxidation of the ring, probably in position 4 (if 4-hydroxy-benzoate is added to the medium, this step is also not needed);

3. Sulfonation of 4-hydroxy-benzoate in the free 3- or 5-positions in the ring (Fig. 10).

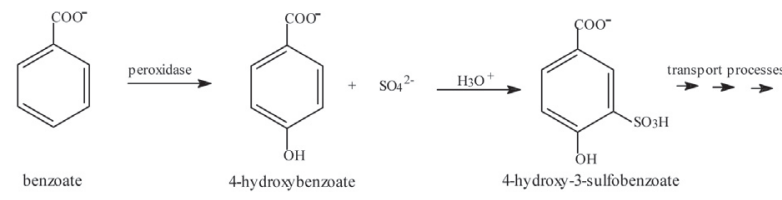

Figure 10. Proposed transformation reactions of secreted benzoate for following sulfate uptake processes.

When the first step or both the first and the second one are not necessary, the lag phase might be shortened so considerably that it would become unnoticeable. It can be reasonably assumed that the kinetics of the third step is much faster than that of the first two steps. However, when sodium sulfite instead of sodium sulfate was added to the nutrient medium, the lag phase became longer by oneweek (unpublished). This could be considered as an additional argument supporting the sulfonation process, for which sulfites $\left(\mathrm{HSO}_{3}^{-}\right)$are not appropriate substrates. The sulfate uptake by sulfonation of 4-hydroxy-benzoate could be specific but more efficient than other ways for sulfate transport. Pseudomonas putida S-313 strain, which is able to consume monoaryls, was found to contain a specific transporter protein (AsfC or AtsB) binding arylsulfonates (Vermeij et al., 1999). Other microorganisms obtain sulfur either from inorganic sulfate or from organosulfur compounds such as arylsulfonate (Valdés et al., 2003).

In the cytosol, 4-hydroxy-3-sulfo-benzoate is most probably hydrolytically desulfonated and the sulfate group becomes a substrate for the sulfate reduction pathway, whereas 4-hydroxy-benzoate (after further metabolic transformations) is assimilated as acetate.

\section{REFERENCE}

Barth L (1871) Ueber die Umwandlung der Oxybenzoësäure in Protocatechusäure und die Constitution der letzteren. Justus Liebigs Ann Chem 159: 230-240.

Cypionka H (1987) Uptake of sulfate, sulfite and thiosulfate by proton-anion symport in Desulfovibrio desulfuricans. Arch Microbiol 148: 144-149.

Cypionka H (1989) Characterization of sulfate transport in Desulfovibrio desulfuricans. Arch Microbiol 152: 237-243.

Fago JK., Popowsky M (1949) Spectrophotometric determination of hydrogen sulfide. Methylene blue method. Anal Chem 21: 732-734.

Fuseler K, Krekeler D, Sydow U, Cypionka H (1996) A common pathway of sulfide oxidation by sulfate-reducing bacteria. FEMS Microbiol Lett 144: 129-134.

Gorny N, Schink B (1994) Complete anaerobic oxidation of hydroquinone by Desulfococcus sp. strain Hy5: indications of hydroquinone carboxylation to gentisate. Arch Microbiol 162: 131-135.

Kertesz MA (2001) Bacterial transporters for sulfate and organosulfur compounds. Res Microbiol 152: 279-290.

Kuever J, Kulmer J, Jannsen S, Fischer U, Blotevogel KH (1993) Isolation and characterization of a new spore- 
forming sulfate-reducing bacterium growing by complete oxidation of catechol. Arch Microbiol 159: 282-288.

LeGall J, Fauque G (1988) Dissimilatory reduction of sulfur compounds. In Biology of Anaerobic Microorganisms, Zehnder AJB, ed, pp 469-586, AJ Wiley \& Sons Inc, New York, Singapore.

Moura I, LeGall J, Lino AR Jr, Peck HD, Fauque G, Xavier AV, DerVartanian DV, Moura JJG, Huynh BH (1988) Characterization of two dissimilatory sulfite reductases (desulforubidin and desulfoviridin) from the sulfatereducing bacteria. Mössbauer and EPR studies. J Am Chem Soc 110: 1075-1082.

Pado R, Pawłowska-Ćwięk L (2004) Monitoring of changes occurring during a long-term incubation of Desulfotomaculum acetoxidans DSM 771. Acta Biol Cracoviensia Ser Bot 46: 101-107.

Pado R, Pawłowska-Ćwięk L, Szwagrzyk J (1994) Heavy metals detoxification in soil performed by sulfate-reducing bacteria. Ekol Pol (Pol J Ecol) 42: 103-123.

Postgate JR (1984) Incubation and growth. In: The Sulfate Reducing Bacteria. 2nd edn. pp 24-40. Cambridge University Press, London.

Rabus R, Widdel F (1995) Conversion studies with substrate analogues of toluene in sulfate-reducing bacterium, strain Tol2. Arch Microbiol 164: 448-451.

Raskin L, Rittmann BE, Stahl DA (1996) Competition and coexistence of sulfate-reducing and methanogenic populations in anaerobic biofilms. Appl Environ Microbiol 62: 3847-3857.

Schink B, Brune A, Schnell S (1992) Anaerobic degradation of aromatic compounds. In Microbial Degradation of
Natural Products, Winkelmann G, ed, pp 220-239. VCH, Weinheim, Cambridge.

Schnell S, Bak F, Pfennig N (1989) Anaerobic degradation of aniline and dihydroxybenzenes by newly isolated sulfate-reducing bacteria and description of Desulfobacterium anilini. Arch Microbiol 152: 556-563.

Silver S, Walderhaung M (1992) Ion transport. In Encyclopedia of Microbiology, Vol. 2: 549-560. Academic Pess INC, San Diego.

Szutowicz A, Kobes RD, Orsulak PJ (1984) Colorimetric assay for monoamine oxidase in tissues using peroxidase and 2,2'-azinodi(3-ethylbenzothiazoline-6-sulfonic acid) as chromogen. Anal Biochem 138: 86-94.

Valdés J, Veloso F, Jedlicki E, Holmes D (2003) Metabolic reconstruction of sulfur assimilation in the extremophile Acidithiobacillus ferrooxidans based on genome analysis. BMC Genomics 4: 51-64.

Van Ommen Kloake F, Bryant RD, Laishley EJ (1995) Localization of cytochromes in the outer membrane of Desulfovibrio vulgaris (Hildenborough) and their role in anaerobic biocorrosion. Anaerobe 1: 351-358.

Vermeij P, Wietek C, Kahnert A, Wüest T, Kertesz MA (1999) Genetic organization of sulfur-controlled aryl desulfonation in Pseudomonas putida S-313. Mol Microbiol 32: 913-926.

Widdel F, Pfennig N (1984) Dissimilatory sulfate- or sulfur-reducing bacteria. In Bergey's Manual of Systematic Bacteriology, Krieg NR, Holt JG, eds, vol 1, pp 663-679. Williams \& Wilkins, Baltimore, London, Tokio. 